\title{
Percentage of Injuries, and Related Factors Among a Group of Medical Students in Cairo University: A Cross-Sectional Study
}

\author{
Hend Aly Sabry DiD, Alaa Abou Zeid, Marwa Salem (D) \\ Department of Public Health and Community Medicine, Faculty of Medicine, Cairo University, Egypt
}

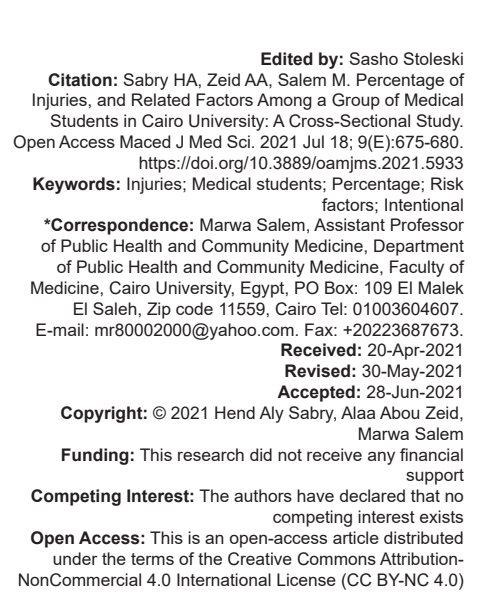

Introduction

Injuries are the leading cause of death and disability worldwide; more than 5 million people die each year because of injuries with an increase of $5.3 \%$ since 1990. This accounts for $9 \%$ of the world's deaths, Years lost because of disability (YLDs) was (12\%) [1], [2]. Injury burden reduction is a vital component of global strategies like the Sustainable Development Goal 3 to "ensure safe lives and promote well-being [2]."

For people between the ages of 15 and 29 years, road traffic injuries are the leading cause of death, with suicide and homicide the second and fourth leading causes of death respectively [1]. About $90 \%$ of injury-related deaths occur in low- and middleincome countries [1]. In 2015, mortality rates were more than twice as high in low- and high-income countries compared to global income averages and motor vehicle occupants had a 3-fold greater mortality than the global average. Egypt shows a road traffic fatality rate of 42 deaths per 100,000 population-one of the highest in the Eastern Mediterranean Region. Reproductive tract infections are also responsible for $1.8 \%$ of all deaths and $2.4 \%$ of all disability-adjusted life years (DALYs) [3].
Previously conducted studies revealed that the prevalence of injuries varies from $14.1 \%$ to $21.9 \%$ among university students [3], [4], [5], [6]. Significant factors associated with sustaining injury were smoking, alcohol use, quarreling behavior, carrying weapon, sports activities, inadequate sleep, psychological distress, falls, threatened by weapon, and verbal bullying [4], [7].

In Egypt, limited attention has been given to injuries as health problems in Egypt. There has been a lack of data on injuries in young adults, including university students, in particular medical students. Therefore, the current study was conducted to explore the percentage, and related factors of injuries among a group of medical students, who constitute an important risk group for accidents and injuries.

\section{Methods}

\section{Study design and setting}

This exploratory cross-sectional study was conducted in Cairo University; namely both in the 
Faculty of Medicine and Faculty of Dentistry/Kasr al Ainy Medical School. It is the largest and oldest medical Institute in the Middle East. It was established the year 1827, along 180 years thousands of doctors graduated, and millions of patients were treated. The number of studying years of the faculty is 6 years as well as the training year, concession period. English is the language of studying. The study targeted Egyptian Medical students during the period from January $15^{\text {th }} 2019$ to April $30^{\text {th }}, 2019$.

\section{Sample size and sampling technique}

To ensure that the demographic and health behavior profiles of the respondents are representing those of the main population in this exploratory study, it was settled upon to choose a large convenient sample of the eligible students from the sample frame of both faculties. Their recruitment was done through distributing and sending a large number of the survey questionnaires- actually 1300 questionnaire- to almost all academic departments along all 6 academic years of faculty of medicine and 5 academic years of faculty of dentistry. It was requested that the questionnaire would be presented and fulfilled before the beginning of their lessons ensuring that it would take them only 20 minutes to be fulfilled. The orientation about the objectives of the study was clearly written in an introductory paragraph in the questionnaire, emphasizing on their right not to participate. A time span of 4 months was considered for distributing and recollecting the questionnaires. From the distributed 1300 questionnaires, only 953 were retrieved and only 807 from them were eligibly complete. It is worth mentioning that students in the faculty of medicine were more accessible than students in the faculty of dentistry.

\section{Data collection tools}

The anonymous questionnaire form was adopted from "Health behavior survey among university students in low- and middle-income countries questionnaire" which was a multi-country study [9]. Only some questions were retrieved from it not for the sake of comparison between countries but for the sake of exploring the situation in Egypt and finding associations between the possible determinants and the outcomes.

The questionnaire form which was presented in English as it is the formal educational language used at the site of the study gathered information on the following sections:

1. Socio-demographics: included age, gender, year of study, religion, residence (on his own or with guardians), marital status, socioeconomic background was assessed by rating their family background as wealthy, quite well off, not very well off, or quite poor.

2. Their academic performance, how would they perceive their general and mental health.
3. Doing vigorous physical activity, taking drugs, alcohol drinking, whether they have problems with sleeping and their body mass index.

4. Whether the injury happened intentionally or unintentionally.

The tool was pilot tested on a sample of 50 students to assess any potential difficulty in questionnaire administration and determining the time needed to complete its fulfillment.

\section{Statistical analysis}

Data entry and analysis were carried out using SPSS 21.0 (SPSS Inc. IBM, USA). The total eligible questionnaires for the final analysis were 807 (response rate of $62 \%$ ). Numerical data were expressed using mean and standard deviation. Categorical variables were reported as percent. Mann Whitney-U test and Chi-square test for independence were used for comparison, odds ratio with $95 \%$ confidence intervals (Cl) was calculated, and $p<0.05$ was considered statistically significant.

\section{Ethics approval}

The study protocol was revised and approved by the Ethics Committee in the Public Health Department, Faculty of Medicine, Cairo University. All subjects were treated according to the Helsinki Declaration of biomedical ethic [9]. Written informed consent was obtained after proper orientation of the participants regarding the objectives of the study, confidentiality of data, as well as the impact of the research. Identifier codes were used in order to ensure freely given responses.

\section{Results}

The worked upon sample included medical students from both Faculty of Medicine and Faculty of Dentistry, with the great majority from the Faculty of medicine about $92 \%$. The sample included nearly equal percent of males and females. Their mean ages were nearly similar of about $20.5 \pm 1.31$ years. Arabic was the most spoken language among the majority $98.5 \%$. Most of them were in the fourth academic year followed by the second academic year. Only a small minority of them were married $(2.0 \%)$. About two-thirds $(66 \%)$ of the sampled females lived off-campus with their parents. More than three-quarters of the participants had quite well-off family background and $<1 \%$ had quite poor family background. The greater percent of both sexes (about 35\%) were very good in their academic performance (Table 1). 
Table 1: Characteristics of the enrolled medical students at Cairo University $(n=807$ )

\begin{tabular}{ll} 
& \\
\hline Characteristics & $(\mathrm{n}=807)$ \\
\hline Age & \\
- Mean \pm SD & $20.5 \pm 1.31$ \\
Gender $\mathrm{n}(\%)$ & \\
- Female & $438(54.3)$ \\
Faculty $\mathrm{n}(\%)$ & \\
- Faculty of medicine & $741(91.8)$ \\
Language spoken most often $\mathrm{n}(\%)$ & \\
- Arabic & $795(98.5)$ \\
- English & $7(0.9)$ \\
- French & $5(0.6)$ \\
Academic year $\mathrm{n}(\%)$ & \\
- First & $64(7.9)$ \\
- Second & $202(25.1)$ \\
- Third & $81(10.0)$ \\
- Fourth & $274(34.0)$ \\
- Fifth & $116(14.4)$ \\
- Sixth & $69(8.6)$ \\
Marital status $\mathrm{n}(\%)$ & \\
- Not married & $790(98.1)$ \\
Religion $\mathrm{n}(\%)$ & \\
- Muslim & $763(94.5)$ \\
- Christian & $38(4.7)$ \\
- No religion & $3(0.4)$ \\
- Others & $3(0.4)$ \\
Residence $\mathrm{n}(\%)$ & \\
- On campus residence & $203(25.0)$ \\
- Off campus (on your own) & $182(22.6)$ \\
- Off campus (with parents/guardians) & $422(52.4)$ \\
Family background $\mathrm{n}(\%)^{*}$ & \\
- Wealthy & $15(1.9)$ \\
- Quite well-off & $613(76.2)$ \\
- Not very well off & $173(21.5)$ \\
- Quite poor & $3(0.4)$ \\
Academic performance $\mathrm{n}(\%)^{*}$ & \\
- Excellent & $123(15.3)$ \\
- Very good & $295(36.8)$ \\
- Good & $212(26.4)$ \\
- Satisfactory & $96(12.0)$ \\
- Not satisfactory & $76(9.5)$ \\
\hline${ }^{*}$ Numbers may count to less than the total because of missed responses, valid percent were used. \\
& \\
\hline
\end{tabular}

Those who reported being injured last year were almost one-quarter $24.9 \%$ of the whole sample. Comparing between reported to have been injured participant students and those who did not report to have been injured, regarding their different characteristics and factors, only those who "perceived" their general health as "well" reported being injured significantly more than those who perceived their general health as poor, with a $p=0.006$ and odds ratio of $1.6(1.1-2.2)$.

No significant differences were seen between the two groups of participant students - injured and not injured - during the last year regarding the other analyzed factors (Table 2). Falling was the most nominated cause of injuries by the participant students $(26 \%)$ followed - with a great gap - by being hit by something (6.3\%) (Figure 1).

Taking drugs was the only factor significantly determining how the injury happened; whether it is intentional or unintentional with $a p=0.01$ highlighting that about one-third $(5,31.3 \%)$ of those who were intentionally injured were taking drugs. The other factors did not have significant effects (Table 3).

\section{Discussion}

This exploratory cross-sectional study revealed that about one quarter $24.9 \%$ of the whole sample reported having a form of injury last year. only those who "perceived" their general health as "well" reported being injured significantly more than those who perceived their general health as poor. Falling was the most nominated cause of injuries by the participant students $(26 \%)$ followed by being hit by something $(6.3 \%)$. These findings are consistent with the results of studies in many developing countries [3], [4], [5], [10]. Drug taking was the only significant determinant that led to intentional injuries rather than unintentional injuries

The factors identified to be associated with injury occurrence will increase the understanding of public health experts of injuries in university communities, and thus better design programs for injury prevention, including information, education, communication campaigns, and programs specifically targeting university students, staff, and university health center professionals. Those who "perceived" their general health as "well" reported being injured significantly more than those who perceived their general health as poor, this might be explained by increase sense of security among them. This finding can be utilized in public health efforts reaching these young people for change strategies in injury prevention and control programs

There was no gender difference as regards the occurrence of injury. This finding was similar to previous studies conducted in several countries [12], [13], [14]. But differ from what was found in a study that reported significant gender differences between 0-17 year's old subjects [4], [6] that being a man was a greater risk factor than being a woman for nonfatal injuries among university students. This difference might be attributed to the setting being a hospital-based study while the current study is a faculty-based study.

As revealed from the current study, the rate of reported unintentional injuries was $(83.5 \%)$ while intentional injury was (16.5\%) among those who answered the question. This finding is close to that declared in an earlier study conducted in Egypt, where unintentional injuries reported by $(95.7 \%)$ and intentional injuries (4.3\%) [6]. However, this finding was higher than that reported by another study conducted in Nigeria, where about $68.7 \%$ of the reported injuries were unintentional [11]. Additionally, a previous study conducted in Michigan, $61.8 \%$ reported an unintentional injury and $38.1 \%$ reported an intentional injury [13], [14]. Lastly, amongst the enrolled students who reported happening of injuries, drug-taking was the only significant determinant that led to intentional injuries rather than unintentional injuries. This finding is important because in accordance to CDC National 
Table 2: Comparison between injured and non-injured students in the previous year regarding their different demographics and characteristics $(n=807)$

\begin{tabular}{|c|c|c|c|c|c|}
\hline Characteristics & Injured $(201,25.0 \%)$ & Not- injured $(606,75.0)$ & Total & $p$ value & Odds ratio $(\mathrm{Cl})$ \\
\hline \multicolumn{6}{|l|}{ Age } \\
\hline - (Mean $\pm S D)$ & $(20.4 \pm 1.1)$ & $(20.5 \pm 1.4)$ & --------- & $0.271^{*}$ & ------- \\
\hline \multicolumn{6}{|l|}{ Gender $\mathrm{n}(\%)$} \\
\hline - Male & $100(49.8)$ & $269(44.4)$ & $369(45.7)$ & $0.182^{\star \star}$ & $1.2(0.9-1.7)$ \\
\hline - Female & $101(50.2)$ & $337(55.6)$ & $438(54.3)$ & & \\
\hline \multicolumn{6}{|l|}{ Residence n (\%) } \\
\hline - Living on his (her) own & $105(52.2)$ & $278(46.0)$ & $383(47.6)$ & $0.122^{\star \star}$ & $1.3(0.9-1.8)$ \\
\hline - Living with parents or guardians & $96(47.8)$ & $326(54.0)$ & $422(52.4)$ & & \\
\hline \multicolumn{6}{|l|}{ Family background $\mathrm{n}(\%)$} \\
\hline - Well off & $153(76.5)$ & $475(78.6)$ & $628(78.1)$ & $0.520^{\text {** }}$ & $0.9(0.6-1.3)$ \\
\hline - Not well off & $47(23.5)$ & $129(21.4)$ & $176(21.9)$ & 0.020 & \\
\hline \multicolumn{6}{|l|}{ General health perception n (\%) } \\
\hline - Well & $91(45.3)$ & $209(34.5)$ & $300(37.2)$ & $0.006^{* *}$ & $1.6(1.1-2.2)$ \\
\hline - Poor & $110(54.70$ & $396(65.5)$ & $506(62.8)$ & & \\
\hline \multicolumn{6}{|l|}{ Mental Health perception n (\%) } \\
\hline - Fairly satisfied & $38(18.9)$ & $119(19.7)$ & $157(19.6)$ & $0.820^{* *}$ & $0.9(0.6-1.4)$ \\
\hline - Not satisfied & $162(80.6)$ & $484(80.3)$ & $646(80.4)$ & & \\
\hline \multicolumn{6}{|l|}{ Alcohol intake n (\%) } \\
\hline - Yes & $9(4.5)$ & $14(2.3)$ & $23(2.9)$ & $0.110^{\star \star}$ & $1.9(0.8-4.7)$ \\
\hline - No & $192(95.5)$ & $592(97.7)$ & $784(97.1)$ & & \\
\hline \multicolumn{6}{|l|}{ Taking drugs $\mathrm{n}(\%)$} \\
\hline -Yes & $21(10.4)$ & $69(11.4)$ & $90(11.2)$ & $0.714^{* *}$ & $0.9(0.5-1.5)$ \\
\hline - No & $180(89.6)$ & $537(88.6)$ & $717(88.8)$ & & \\
\hline \multicolumn{6}{|l|}{ Having problems with sleeping } \\
\hline - Yes, most of time & $64(31.8)$ & $161(26.6)$ & $225(27.9)$ & $0.149^{\star \star}$ & $1.3(0.9-1.8)$ \\
\hline- No & $137(68.2)$ & $445(73.4)$ & $582(72.1)$ & & \\
\hline \multicolumn{6}{|l|}{ Practicing vigorous exercise $\mathrm{n}(\%)$} \\
\hline - Yes & $31(15.4)$ & $87(14.4)$ & $118(14.6)$ & $0.712^{\star \star}$ & $0.9(0.6-1.4)$ \\
\hline - No & $170(84.6)$ & $519(85.6)$ & $689(85.4)$ & & \\
\hline \multicolumn{6}{|l|}{ Body mass index $\mathrm{n}(\%)$} \\
\hline - Underweight & $25(13.3)$ & $80(13.7)$ & $105(13.6)$ & $0.250^{\text {** }}$ & $0.9(0.6-1.6)$ \\
\hline - Normal & $93(49.5)$ & $278(47.8)$ & $371(48.2)$ & $0.250^{\star \pi}$ & Reference \\
\hline - Overweight & $45(23.9)$ & $171(29.4)$ & $216(28.1)$ & & $1.3(0.8-1.9)$ \\
\hline - Obese & $25(13.3)$ & $53(9.1)$ & $78(10.1)$ & & $0.7(0.4-1.2)$ \\
\hline
\end{tabular}

Table 3: Comparison between students considering how the injury happened in the previous year regarding their different demographics and characteristics $(n=97,12 \%) \#$

\begin{tabular}{|c|c|c|c|c|c|}
\hline Characteristics & Unintentional (81) & Intentional (16) & Total & $p$ value & Odds ratio $(\mathrm{Cl})$ \\
\hline \multicolumn{6}{|l|}{ Age } \\
\hline - (Mean \pm SD) & $(20.3 \pm 0.93)$ & $(20.5 \pm 1.3)$ & -------- & $0.261^{*}$ & 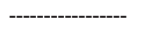 \\
\hline \multicolumn{6}{|l|}{ Gender n (\%) } \\
\hline - Male & $47(58)$ & $13(81.3)$ & & $0.081^{* *}$ & $0.3(0.1-1.2)$ \\
\hline - Female & $34(42)$ & $3(18.8)$ & & & \\
\hline \multicolumn{6}{|l|}{ Residence n (\%) } \\
\hline - Living on his (her) own & $40(50)$ & $12(75)$ & $52(54.2)$ & $0.060^{* *}$ & $0.3(0.1-1.1)$ \\
\hline - Living with parents or guardians & $40(50)$ & $4(25)$ & $44(45.4)$ & & \\
\hline \multicolumn{6}{|l|}{ Family background $\mathrm{n}(\%)$} \\
\hline - Well off & $62(77.5)$ & $13(81.3)$ & $75(78.1)$ & $0.741^{* *}$ & $0.8(0.2-3.1)$ \\
\hline - Not well off & $18(22.5)$ & $3(18.8)$ & $21(21.9)$ & & \\
\hline \multicolumn{6}{|l|}{ General health perception $\mathrm{n}(\%)$} \\
\hline - Well & $36(44.4)$ & $9(56.3)$ & $45(46.4)$ & $0.380^{\star *}$ & $0.6(0.2-1.8)$ \\
\hline - Poor & $45(55.6)$ & $7(43.8)$ & $52(53.6)$ & & \\
\hline \multicolumn{6}{|l|}{ Mental Health perception n (\%) } \\
\hline \multicolumn{6}{|l|}{ - Fairly satisfied } \\
\hline \multirow[t]{2}{*}{ - Not satisfied } & $18(22.2)$ & $6(37.5)$ & $24(24.7)$ & $0194 * *$ & $0.5(0.2-1.5)$ \\
\hline & $63(77.8)$ & $10(62.5)$ & $73(75.3)$ & $0.194^{n}$ & \\
\hline \multicolumn{6}{|l|}{ Alcohol intake n (\%) } \\
\hline -Yes & $4(4.9)$ & $1(6.3)$ & $5(5.2)$ & $0.623^{\star *}$ & $0.8(0.1-7.5)$ \\
\hline - No & $77(95.1)$ & $15(93.8)$ & $92(94.8)$ & & \\
\hline \multicolumn{6}{|l|}{ Taking drugs $\mathrm{n}(\%)$} \\
\hline - Yes & $5(6.2)$ & $5(31.3)$ & $10(10.3)$ & $0.010^{* *}$ & $0.14(0.03-0.6)$ \\
\hline - No & $76(93.8)$ & $11(68.8)$ & $87(89.7)$ & & \\
\hline \multicolumn{6}{|l|}{ Having problems with sleeping } \\
\hline - Yes, most of time & $26(32.1)$ & $8(50)$ & $34(35.1)$ & $0.173^{\star *}$ & $0.5(0.2-1.4)$ \\
\hline- No & $55(67.9)$ & $8(50)$ & $63(64.9)$ & & \\
\hline \multicolumn{6}{|l|}{ Practicing vigorous exercise $\mathrm{n}(\%)$} \\
\hline - Yes & $73(90.1)$ & $13(81.3)$ & $86(88.7)$ & $0.260^{\star *}$ & $2.1(0.5-8.9)$ \\
\hline - No & $8(9.9)$ & $3(18.8)$ & $11(11.3)$ & & \\
\hline \multicolumn{6}{|l|}{ Body mass index $\mathrm{n}(\%)$} \\
\hline - Underweight & $8(10.5)$ & $3(20)$ & $11(12.1)$ & $0.631^{* *}$ & $0.6(0.1-2.8)$ \\
\hline - Normal & $32(42.1)$ & $7(66.7)$ & 39 (42.9) & & ------- \\
\hline - Overweight & $24(31.6)$ & $4(26.7)$ & $28(30.8)$ & & $0.8(0.2-2.9)$ \\
\hline - Obese & $12(15.8)$ & $1(6.7)$ & $13(14.3)$ & & $0.4(0.04-3.4)$ \\
\hline
\end{tabular}

were used. ${ }^{\star} M a n n-W h i t n e y-U$ test, ${ }^{\star *}$ Chi-square test.

Action Plan for Child and Youth Injury Prevention [15] implementing effective prevention strategies to prevent drug use will contribute to reducing intentional injuries in accordance. 


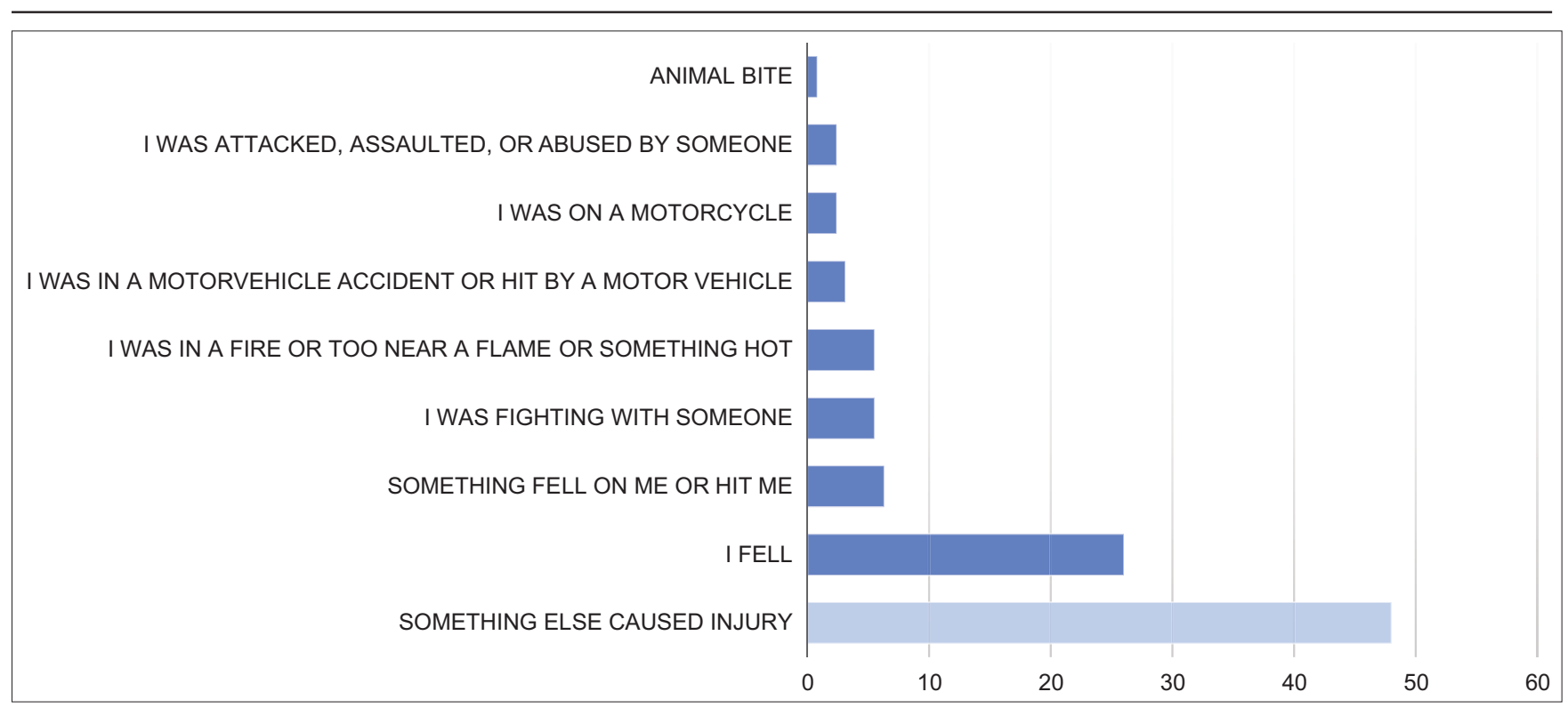

Figure 1. Causes of the most serious injury during the last year among participant students

\section{Limitations of study}

Although findings did provide some insight about the issue, they are not nationally representative. However, the current study was conducted to shed light on the frequency of injuries and associated factors among medical students not to generalize the findings; further studies on a national level are highly recommended. writing the manuscript. MRS has made substantial contributions to the acquisition of data and writing the manuscript. HAS was involved in drafting the manuscript (methods and results section) and revising it critically for important intellectual content and statistical analysis. All the authors read and approved the final version of the manuscript.

\section{Conclusion and Recommendations}

The current study revealed that there is a need to raise medical students' awareness about the magnitude and burden of injuries. Injury control and prevention programs should be done through combination of mass media and medical school interventions through establishing and applying an educational and training program targeted at injury prevention and control among medical school students as a part of the regular educational curriculum mainly drug use.

\section{Acknowledgments}

The authors are thankful to medical students for their participation in the current study.

\section{Authors' Contributions}

A.A has made substantial contributions to conception and design, and interpretation of data, and

\section{References}

1. World Health Organization. Injuries and Violence: The Facts. Geneva: World Health Organization; 2020. Available from: http://www.who. int/violence_injury_prevention/key_facts/en/ index.html. [Last accessed on 2020 Oct 08].

2. James SL, Castle CD, Dingels ZV, Fox JT, Hamilton EB, Liu Z, et al. Global injury morbidity and mortality from 1990 to 2017: Results from the global burden of disease study 2017. Inj Prev. 2020;26(Suppl 1):i96-114. https://doi.org/10.1136/ injuryprev-2019-043494corr1 PMid:32989006

3. Sengoelge M, Laflamme L, El-Khatib Z. Ecological study of road traffic injuries in the eastern Mediterranean region: Country economic level, road user category and gender perspectives. BMC Public Health. 2018;18(Suppl 1):236. https://doi. org/10.1186/s12889-018-5150-1

PMid:29433458

4. Shi X, Wheeler KK, Shi J, Stallones L, Ameratunga S, Shakespeare $\mathrm{T}$, et al. Increased risk of unintentional injuries in adults with disabilities: A systematic review and metaanalysis. Disabil Health J. 2015;8(Suppl 2):153-64. https://doi. org/10.1016/j.dhjo.2014.09.012 PMid:25458975

5. Day HR, El-Setouhy M, El-Shinawi M, Assem A, Ismail M, Salem M, et al. Young Egyptians' perceptions, attitudes and knowledge of injuries. Injury Prev. 2010;16(Suppl 5):348-51. https://doi.org/10.1136/ip.2009.024224 PMid:20587813

6. Yiengprugsawan V, Stephan K, McClure R, Kelly M Seubsman S, Bain C, et al. Risk factors for injury in a national 
cohort of 87,134 Thai adults. Public Health. 2012;126(1):33-9. https://doi.org/10.1016/j.puhe.2011.09.027

PMid:22137094

7. Jildeh C, Abdeen Z, Al Sabbah H, Philalithis A. Unintentional injuries among school-aged children in Palestine: findings from the national study of Palestinian schoolchildren (HBSCWBG2006). Int J Popul Res. 2013;2013:629159. https://doi. org/10.1155/2013/629159

8. Peltzer K, Pengpid S. Factors associated with unintentional injury among university students in 26 countries. Public Health Nurs. 2015;32(Suppl 5):440-52. https://doi.org/10.1111/ phn. 12179

PMid:25644243

9. WMA. World Medical Association Declaration of Helsinki: Ethical Principles for Medical Research Involving Human Subjects; 2013. Available from: https://www.wma.net/policies-post/wmadeclaration-of-helsinki-ethical-principles-for-medical-researchinvolving-human-subjects. [Last accessed on $2021 \mathrm{Feb} 20$ ]. https://doi.org/10.1515/9783110208856.233 PMid:24452042

10. Jildeh C, Abdeen Z, Al Sabbah H, Philalithis A. Unintentional injuries among school-aged children in Palestine: Findings from the National Study of Palestinian Schoolchildren. Int J Popul Res. 2013;2013:629159. https://doi.org/10.1155/2013/629159

11. Nmor J, Nwaka K, Goto K, Toyosawa J, Fujita D. High rate of injuries among students in Southern Nigeria: An urgent call to action. Sci Res. 2013;5(Suppl 12):1965-75. https://doi. org/10.4236/health.2013.512266

12. Wahdan MM, Sayed AM, Abd Elaziz KM, El-Hoseiny MM, Al-Gwaily MM. Prevalence of injuries among high schoo students in Eastern and Western parts of Cairo, Egypt. Injury. 2016;47(Suppl 12):2650-4. https://doi.org/10.1016/j. injury.2016.09.024 PMid:27771039

13. El-Sayed H, Hassan F, Gad S. Cross-sectional study of injury among school children in Ismailia city, Egypt. The Egyptian partnership in development research program. Injury Prev J. 2012;18(Suppl 1):101136. https://doi.org/10.1136/ injuryprev-2012-040590d.64

14. Centers for Disease Control and Prevention. National Action Plan for Child Injury Prevention. National Center for Injury Prevention and Control, Centers for Disease Control and Prevention; Atlanta, GA, USA: Centers for Disease Control and Prevention; 2012. https://doi.org/10.1037/e308822004-001 